\title{
Desfazendo a mala: memórias de imigrantes na mídia
}

\author{
Lucia Santa Cruz'
}

\begin{abstract}
Resumo
Este artigo procura analisar como a memória tem assumido um lugar relevante na construção de identidade social, no caso de imigrantes, a partir de um certo desencantamento com a história, que passa a ocupar um posto secundário no resgate do passado. Esta análise se faz a partir da avaliação interpretativa de produtos midiáticos que documentam a vida e a trajetórias de populações que deixam suas terras natais em busca de novos horizontes. Este artigo estuda em especial a série de 13 documentários do canal Futura Chegados, exibida de maio a agosto de 2007, em que cada episódio é dedicado a uma leva migratória para o Brasil, optando por organizar o conteúdo a partir da memória dos descendentes desses imigrantes. Ao mesmo tempo, se faz um contraponto do que se poderia chamar de um autêntico "boom" da memória, com filmes, documentários, peças, livros e outras produções girando em torno do arsenal memorial.
\end{abstract}

Palavras-chave: memória, identidade, resgate cultural, museificação, documentário

\begin{abstract}
This article tries to analyse like the memory has been assuming a relevant place in the construction of social identity, in case of immigrants, from a certain disappointment with History, which starts to occupy a secondary post in the redemption of the past. This analysis does to itself from the interpretative evaluation of midia products that document life and trajectories of populations that leave their birth-places in search of new horizons. This article studies in particular the Futura Channel series of 13 documentaries - Chegados, in which each episode is dedicated to a migratory group for Brazil, opting to organize the content from the memory of the descendants of these immigrants. At the same time, there is done a counterpoint of which it might call an authentic "boom" of the memory, with movies, documentaries, books, plays and other productions getting around the memorial arsenal
\end{abstract}

Keywords: memory, identity, cultural redemption, museums, documentary

1Professora da Escola de Comunicação da UFRJ, Jornalista, Doutoranda e Mestre em Comunicação pela UFRJ. estuda a representação da responsabilidade social empresarial nos discursos jornalisticos. Assessora de Comunicação do Instituto Oswaldo Cruz de Seguridade Social, vinculado à (Fiocruz), trabalhou em jornais diários, emissoras de rádio e assessorias de comunicação. 


\section{Sob a sombra da memória}

Na introdução de seu livro Imagined Communities - Reflections on the origin and spread of nationalism, Benedict Anderson, depois de apontar os três paradoxos com que os teóricos do nacionalismo se defrontam1, sugere a seguinte definição para nação - uma comunidade política imaginada - e imaginada como sendo, ao mesmo tempo, limitada e soberana. Discorrendo sobre cada palavra que compõe esta expressão, Anderson deixa claro que, em sua visão, a era do fim do nacionalismo, tão profetizada, está fora do nosso horizonte.

[Nation] s imagined because the members of even the smallest nation will never know most of their fellow-members, meet them, or even hear of them, yet in the minds of each lives the image of their communion. (...)all communities larger than primordial villages of face-to-face contact (and perhaps even these) are imagined. (...) The nation is imagined as limited because even the largest of them, encompassing perhaps a billion living human beings, has finite, if elastic, boundaries, beyond which lie other nations. (...) It is imagined as sovereign because the concept was born in an age in which Enlightenment and Revolution were destroying the legitmacy of the divinely-ordained, hierachical dynastic realm. (...) Finally, it is imagined as a community, because, regardless of the actual inequality and exploitation that may prevail in each, the nation is always conceived as a deep, horizontal comradeship.(ANDERSON, 1991:15-16)2

Pensar as nações como comunidades imaginadas não quer dizer que sejam falsas ou fabricadas, mas que são artefatos culturais - e como tais, só existem no enredamento de um determinado tecido social, o qual, por sua vez, está situado numa determinada temporalidade. Ao mesmo tempo, é curioso ver de que maneira a noção de nação como uma confraria se manifesta em diversos momentos, especialmente em produtos midiáticos que abordam assuntos que tangenciam identidades nacionais.

Ao formularmos a noção de comunidade imaginada, tecemos conexão com o imaginário social, uma instância que opera o tempo todo entre pertencimentos e tradições, construindo um passado que resgate o presente.

Ainda que concordemos com Anderson, e admitamos que o nacionalismo não chegou exatamente a sucumbir, não há como negar que hoje, entretanto, as noções de nação e tradição, bem como as de Estado, estão enfraquecidas, o que ocorre também com a idéia de uma 
história linear, por meio da qual se conhecia o passado para viver o presente e construir o futuro. Beatriz Sarlo é uma das vozes que denuncia este esmaecimento, ao dizer que o passado é reconstrução do que fazemos a partir do presente.

A mesma visão é compartilhada por Frederic Jameson, ao postular que a historicidade não é nem uma representação do passado nem uma representação do futuro,mas antes de mais nada deve ser definida como uma percepção do presente como história, "that is, as a relationship to the present which somehow defamilirizes it and allows us that distance from immediacy which is at length characterized as a hipostical perspective. (Jameson, 1991,: 284)3

\section{Construindo o lugar da memória}

No modernismo, se acredita em fazer a história, rompendo com o passado para inaugurar futuros. Época de revoluções, de se projetar a crença na utopia. O contemporâneo se irradia em passados e presentes, mas sem perspectivas de futuros. Instalada a crise do futuro, vivida numa espécie de ressaca dos sonhos, encontramos as ruínas do passado. Portanto, se a história jaz em fragmentos, então se vai construir o lugar da memória.

A memória, especialmente no que diz respeito à construção de identidades e ao desenho do sentimento de nação, hoje assume o papel de ser uma narrativa que forneça sentido individual e coletivo, sendo que todas as memórias que temos são filtradas pela midia. Não são memórias advindas do lembrar, são sempre mediadas. Basta encontrar uma foto na gaveta para desencadear um processo de memória midiática.

A fragmentação do discurso histórico levou a história social e cultural a deslocar seu estudo para as margens da sociedade modernas, modificando a noção de sujeito e a hierarquia dos fatos, destacando os pormenores cotidianos articulados numa poética do detalhe e do concreto, como destaca Sarlo (2007: 43).

"Nas últimas décadas, a história se aproximou da memória e aprendeu a interrogá-la; a expansão das 'histórias orais' e das micro-histórias é suficiente para provar que este tipo de testemunho obteve uma acolhida tanto acadêmica quanto midiática. (SARLO, ibidem)

A pesquisadora argentina sublinha ainda a atual tendência acadêmica e do mercado de bens simbólicos, que se propõe a reconstituir a textura da vida e a verdade abrigadas na rememoração da experiência, 
a revalorização da primeira pessoa como ponto de vista, a reivindicação de uma dimensão subjetiva, tendência essa que se infiltra nos estudos do passado e do presente. "A história oral e o testemunho restituíram a confiança nessa primeira pessoa que narra sua vida (privada, pública, afetiva, política) para conservar a lembrança ou para reparar uma identidade machucada." (SARLO, 2007:19)

\section{Cultura da memória}

O crítico e professor de literatura, de origem alemã, Andreas Huyssen, ressalta que um dos fenômenos culturais e políticos mais surpreendentes dos anos recentes é a emergência da memória como uma das preocupações culturais e políticas centrais das sociedades ocidentais. "Esse fenômeno caracteriza uma volta ao passado que contrasta totalmente com o privilégio dado ao futuro, que tanto caracterizou as primeira décadas da modernidade do século XX" (HUYSSEN, 2000: 9).

Para este autor, a ascensão da "cultura da memória" a partir dos anos 1980 é gerada por diversos fatores, incluindo eventos políticos como o fim das ditaduras na América Latina, a queda do muro de

182 Berlim, o colapso da União Soviética e o fim do apartheid. Huyssen destaca também o crescente foco cultural nas políticas de identidade $\mathrm{e}$ nos estudos sobre minorias, embora considere que a maior parte do "culto à memória" é fruto do naufrágio do imaginário de utopias futuras.

A cultura da memória tem diferentes intensidades em diferentes partes do mundo, e as lutas por um futuro melhor evidentemente não desapareceram. Mas, para mim, um dos aspectos mais interessantes da globalização cultural tem sido o deslocamento transnacional do discurso da memória do Holocausto para contextos completamente diferentes e implausíveis na América Latina, África e Ásia. A legitimidade política, ao que parece, tem de ser garantida cada vez mais pelo modo como lidamos com nossos passados nacionais do que pelas formas de imaginarmos o futuro.(HUYSSEN, 2005:102)

O tempo próprio da lembrança é o presente, de acordo com Deleuze (apud SARLO, 2005:10), isto é, o único tempo apropriado para lembrar e, também, o tempo do qual a lembrança se apodera, tornando-o próprio.

\section{Panorâmica}


Esta eclosão de discursos da memória pode ser verificada rapidamente ao se folhear um caderno de cultura de um jornal diário de uma grande capital brasileira. Invariavelmente haverá nele uma reportagem, nota, artigo ou coluna que trate de algum produto cultural cuja base seja a memória. No início do segundo semestre deste ano, diversas produções partiam da memória como resgate para reconstruir a história.

Entre a amostra, podemos citar o fato de até o final de agosto de 2007, no Rio de Janeiro, estava em cartaz a peça Avós. Mulheres e Couves Portuguesas, que conta a história de uma imigrante portuguesa que veio para o Brasil aos 14 anos de idade. Ao se deparar com o próprio envelhecimento, ela decide deixar suas histórias escritas para a neta. Na reconstrução das memórias vão sendo construídas as fases da infância, juventude e maturidade. O espetáculo é uma adaptação do livro Não se fazem mais avós como antigamente, de Nãna Pirez. Três atrizes se revezavam no palco para viver as diferentes fases da protagonista, utilizando em cena uma série de caixas, baús e malas de madeira que, ao se abrirem, revelam as reminiscências imagéticas da vida da imigrante.

Outro exemplo pertinente é o documentário realizado pela cineasta e apresentadora do canal de TV MTV Marina Person sobre seu pai, o também cineasta Luiz Sérgio Person, morto em um acidente de carro aos 39 anos, quando a filha tinha apenas 7 anos. A realizadora admite que o filme, com estréia em agosto deste ano, é uma viagem pessoal pela vida e a obra de seu pai, que dirigiu entre outros títulos São Paulo S/A e O Caso dos Irmãos Naves. A partir de entrevistas com familiares e com pessoas que conviveram com o diretor, Marina buscou um resgate de lembranças pessoais ao mesmo tempo em que traça um retrato da importância da obra de seu pai. Não se trata de um documentário que se destina a traçar um perfil de um grande vulto. Em entrevista à Coluna Dois cafés e a conta, da Revista de O Globo, de 29/7/2007, Marina admite que o filme "é uma forma de não ficar só no luto", ao mesmo tempo que considera que "é um filme de descoberta, não é biografia filmada, reconstituição ou investigação."

Também foi um acidente de carro o responsável por tirar a vida do escritor W. G. Sebald, que usou a primeira pessoa para construir um olhar de memória em seu livro de estréia Os Emigrantes, de 1996. Ele mesmo um imigrante alemão que viveu mais de 30 anos na Inglaterra, onde lecionou literatura alemã, Sebald era dono de um estilo único, que mesclava ficção com realidade, bem como fotografias, dispostas sempre como instantâneos do cotidiano (o que explica porque tantas fotos de objetos em seus livros - um efeito de real, de vivido, de 
experimentado) e escreveu ainda Os Anéis de Saturno (1998), Vertigo (1999) e Austerlitz (2001).

O ponto crucial para Sebald não é memória em um sentido genérico total, entretanto, mas o ponto em que o custo de não recordar substitui estratégias protetoras para a sobrevivência, no momento mais adiantado da vida quando experiências ou saberes dolorosos ou horríveis, reprimidos ao longo da existência, se tornam o centro da vida de uma pessoa.

No conto Ambos Adelwarth, de Os Emigrantes, o narrador procura descobrir os contornos da existência de um obscuro tio-avô, exatamente o personagem-título, através de minuciosas "investigações" biográficas que the consomem vários anos de pesquisa intermitente. É um trabalho feito de muitas conversas com familiares próximos ou pessoas que o conheceram, da exumação de álbuns cheios de velhas fotografias e postais ilustrados, ou da exegese de um diário escrito pelo avô, em letra miudinha, num calendário de bolso de 1913.

"Como mesmo as mais insignificantes lembranças daqueles tempos, extraídas de uma profundeza aparentemente inesgotável, fossem de uma extraordinária precisão, ouvindo consegui paulatinamente me convencer de que o tio Adelwarth tinha um incrivel depositório de lembranças, mas pouca capacidade de estabelecer uma ligação entre eleas. Por isso contar se tornava para ele uma tortura e uma tentativa de libertação, uma espécie de salvação e ao mesmo tempo um implacável modo de se autodestruir. (...) "A lembrança, acrescenta ele com uma espécie de pós-escrito, muitas vezes me parece uma espécie de tolice. Ela nos deixa de cabeça pesada e tonta, como se não olhássemos para trás no tempo, mas contemplássemos a terra lá embaixo, de grande altura, de uma dessas torres que se perdem no céu"' última anotação da agendinha do tio-avô Adelwarth. (SEBALD, 2002:146)

Os relatos de Sebald não são um registro de nostalgia, no sentido de gosto pelo passado. Aqui, a memória é responsável pela formatação da identidade. É um inventário da infância, inventário de esperanças do futuro, inventário de esperanças não-realizadas. O narrador nunca sobressai. Há nele uma espécie de invisibilidade, de apagamento voluntário, como se o seu lugar fosse apenas o da escuta. Ele ouve e depois conta. Ele vê e depois descreve. Ele vive e depois recorda. Mas faz tudo isto excluindo-se do cenário, como se estivesse fora de campo - um termo particularmente adequado, se pensarmos nas fotografias (granulosas e sem legendas) por ele intercaladas no texto, às vezes de 
forma enigmática. É como se a função primeira do narrador fosse a de organizar as «torrentes» da memória. A sua e a dos outros.

Interessante pensar sobre o título original em alemão de $O s$ Emigrantes, Die Ausgewanderten. Como em geral em quase todos os vocábulos naquela língua, este é uma composição de diferentes palavras que adquirem novos sentidos. Nela há o verbo no infinitivo wandern, igual ao inglês wander, ',vaguear', inclusive carregando uma idéia de não ter rumo. Um wanderer em inglês é o que se define como sujeito vagabundo; itinerante, pessoa que perambula. No alemão é a mesma idéia. A preposição aus é o 'out' do inglês. E o prefixo ge indica o Perfekt, tempo verbal semelhante com o nosso particípio do português, dai gewandern, referindo-se aos que praticaram a ação de perambular, vagar sem rumo.

Sendo assim, ficamos com a idéia de que o Auswandern é aquele que vaga sem rumo para fora, no caso do seu país ou localidade que habita, ou seja, que é veladamente expulso sem planejamento de destino. E enquanto vaga, a memória o constitui, o conduz, dando-lhe sua identidade no mundo.

\section{Memória e identidade}

A memória como força propulsora da identidade é, da mesma maneira, o principal eixo da série Chegados, exibida pelo canal de televisão Futura4. São 13 episódios de 30 minutos, exibidos semanalmente, desde o dia 26 de maio até o dia 31 de agosto de 2007 , em que através de entrevistas com pessoas famosas e com pessoas comuns, são contadas as histórias de imigrantes que contribuíram para a formação do Brasil contemporâneo. Usando linguagens diferentes, como animação, grafismo, músicas típicas em roupagem de música eletrônica e um ritmo de videoclip, a série mostra histórias de vida de imigrantes que, pelos mais variados motivos, sairam de suas cidades de origem e vieram construir uma nova vida no Brasil.

A série, que venceu o Pitching 5 do canal Futura, foi criada pela produtora Bossa Nova Films, a partir de uma idéia das diretoras Paula Cosenza e Tuca Paoli. Integrantes de um grupo internacional de mulheres que trabalham com comunicação, o Madremedia, as diretoras se conheceram na condição de imigrantes em Londres. Conceberam então uma proposta de retratar a imigração a partir de depoimentos de imigrantes e seus descendentes. Segundo elas, o nome da série foi escolhido por trazer a idéia de proximidade e intimidade e reforça a importância de cada imigrante junto à história do país. Como pano de fundo, os principais fluxos migratórios ocorridos no país. Os episódios 
falam de imigrantes de Japão, Portugal, Itália, Rússia, França, Alemanha, Chile, Moçambique, China, Polônia, Hungria, Armênia e Libano.

Embora alardeie a inovação no enfoque dado ao tema e o aspecto multimídia da linguagem, o formato do programa segue uma regularidade em todos os episódios. A abertura mostra uma mala em primeiro plano, com ideogramas que rolam pela tela, enquanto ao fundo vemos pessoas andando apressadamente - ou, sendo mais precisa, não exatamente pessoas, mas apenas suas pernas, movendo-se freneticamente, umas indo outras voltando. O ritmo é acelerado, as imagens se sucedem em cortes secos, a mala "passeia" pela tela, uma voz em off cita nomes de pessoas de diferentes idiomas, até dizer: "sorria, você está sendo filmado", quando ocorre um zoom na alça da mala e um grafismo simula uma mala menor que abre, identificando a série e logo abaixo o episódio do dia.

As primeiras cenas de todos os episódios também seguem um padrão. São invariavelmente imagens de lugares típicos dos países retratados, mesclados com fotos do cotidiano dos povos. A cada 30 segundos, a imagem congela em uma foto de época, sobre a qual entram dados históricos sobre o movimento migratório do povo retratado no episódio. Não há narração em off, nem qualquer outra interferência que indique o roteiro do programa. Para finalizar esta sequência, um mapa (ou em alguns episódios um globo, que gira a partir do Brasil) aparece, a câmera passeia sobre ele, até fixar-se no país retratado.

Em seguida, começa o primeiro bloco de depoimentos, no qual as pessoas se apresentam. São famosos, como a atriz Eva Todor no programa da Hungria, a cantora Zizi Possi no episódio da Itália ou o escritor Mário Prata no de Portugal. E são pessoas comuns, alguns imigrantes outros descendentes, que dizem seu nome, sua profissão e começam a dar seus depoimentos. Este é o único bloco em que há titulagem: quando os depoentes aparecem pela primeira vez seu nome surge na tela.

Enquanto falam, surgem fotos, acervos pessoais, álbuns de família, baús que vão se abrindo para quem assiste. $O$ entrevistador não aparece, os depoentes vão contando a história de seus antepassados (ou a sua própria) direto para a tela, como se conversassem com o telespectador. O tom do programa é informal, as tomadas são feitas nas casas das pessoas ou em seus locais de trabalho, lembrando uma conversa na cozinha da avó de um amigo de infância. Todos os depoentes estão à vontade, cometem falhas nas datas históricas, se equivocam, se corrigem. A analista de conteúdo do Futura, Renata Couto, destaca em artigo o lugar da memória na narração apresentada em Chegados: 
A nossa série é feita de bons contadores de história que falam do universo do imigrante, do seu sentimento de (não) pertencimento, de angústia e de descoberta. Por isso, em Chegados, queremos trazer à tona ícones de uma cultura que constroem a memória pessoal e coletiva. Memória olfativa, gustativa, cultural, afetiva. Através dos cheiros e sabores, é possivel recompor situações, contar, e (por que não?) criar histórias. Note-se que a memória é ativa na medida em que esses elementos se modificam no novo contexto, e junto com as referências brasileiras, fundam uma nova realidade comum. Para o Canal Futura, Chegados é, antes de tudo, uma possibilidade de enxergar no outro o que nós somos, um tema demasiado oportuno para um tempo em que se discutem a diversidade e a tolerância cultural no mundo. (COUTO, 2007)

Há emoção, muitos choram, riem, cantam, interrompem o depoimento para se recuperar de um sentimento mais forte, como quando no episódio de Portugal, o fotógrafo João Sal narra a dispersão das cinzas da mãe na cidade portuguesa do Porto. Não há, porém, nostalgia. O fio condutor é a memória, que privilegia os aspectos bons do passado e da outra cultura. Existem exceções, como no episódio sobre a Amênia, em que se relembra o massacre imposto pelo império turco-otomano aos armênios em 1915. O ator Stepan Nercessian, filho de pai armênio e mãe cearense, descreve no programa como seu pai consegui fugir da perseguição turca, que assassinou mais de um milhão de armênios.

Os depoimentos são agrupados em blocos, que não são identificados por nenhuma legenda ou título, mas que mantêm uma unidade e são introduzidos pelos próprios depoentes. O primeiro, como já foi dito, é o da apresentação. Depois vem como a família (ou a própria pessoa, no caso dos imigrantes que falam) chegou ao Brasil, o que as trouxe para este país. São histórias de origem, da formação das familias - muitos dos antepassados vêm de regiões diferentes do mesmo pais e se conhecem no Brasil, como os avós da jornalista Carol Badra, do episódio sobre o Libano, que tiveram um casamento arranjado pela colônia libanesa - ela com 12 anos, ele com 40.

Depois vêm os costumes do povo em questão - como foi crescer naquela cultura, do que se lembra mais, o que mais gostava. Há depoimentos curiosos, como o da jornalista Edith Elek, que conta que viveu numa pequena Budapeste brasileira até os 20 anos de idade, pois só convivia com húngaros, a ponto de seu primeiro marido comentar, quando pessoas citavam fatos ocorridos no Brasil dos quais ela não se recordava (embora seja contemporânea a eles), que à época ela "morava" na Hungria. "Eu sei mais músicas folclóricas da Hungria do 
que qualquer húngaro hoje", comenta. Fala semelhante à do comerciante Nelson Kao, filho de chineses da Ilha de Formosa. "Tem algumas coisas que trago que sou mais chinês que os chineses de lá, porque eu trago a imagem do que é chinês."

Há um bloco sobre a língua, as dificuldades de aprendizado ou os fatos curiosos, como no episódio sobre Portugal - mesma língua, outro idioma, segundo o escritor Mário Prata. O bloco seguinte é o das comidas, da culinária, um apelo à memória sensorial, sempre retratado com imagens de pratos típicos, às vezes com grafismos e artes. No episódio do Líbano, uma das entrevistadas é a chefe de cozinha Leila Youssef, que mostra na tela a preparação dos pratos, ao mesmo tempo em que relembra como sua mãe fazia o preparo das mesmas comidas e afirma que a língua é um instrumento forte de transmitir a tradição de uma cultura, mas que é na culinária que esta cultura está mais viva.

O bloco final sempre é uma resposta à pergunta: são brasileiros ou estrangeiros? Muitos dos depoentes se naturalizaram brasileiros, outros conservaram sua nacionalidade mas se auto-proclamam filhos do país. Os descendentes são unânimes. "Sou brasileira de origem húngara, com forte influência da sua origem, mas sou brasileira", diz Edith Elek.

Por trás de cada episódio, está a intenção de explicitar a forma como cada indivíduo ajuda a construir a história de um país. $O$ indivíduo, com seus traços próprios, seus costumes, seus hábitos, sua origem e especialmente sua memória, é um elemento fundamental na formação identitária - é o que parece apontar a série. Isso fica claro no apelo "Conte a sua história", um link existente no site do Canal Futura, e que aponta para um site com informações sobre os episódios da série, outros depoimentos não filmados sobre imigrantes do mesmo país e a possibilidade de qualquer pessoa narrar sua vida.

O link aponta para um formulário do Museu da Pessoa, uma iniciativa criada em São Paulo em 1991 e que hoje tem núcleos em quatro países - Brasil, Canadá, Estados Unidos e Portugal. A idéia original era a implantação de um museu para a preservação de histórias de vida, organizadas em base digital. $O$ museu possui um espaço físico, mas com o surgimento da Internet, ampliou seu alcance, permitindo que qualquer pessoa registre seu depoimento:

A missão do Museu da Pessoa é promover a democratização da memória social, por meio da valorização de histórias de vida de todas as pessoas da sociedade para contribuir com a construção de uma sociedade mais justa, democrática e baseada na compreensão e respeito pelo outro. Nosso objetivo é constituir uma rede virtual de histórias de vida democrática e pluralista, 
que promova ação comunicativa entre os grupos sociais.(MUSEU DA PESSOA, 2007)

Depois de um breve cadastro, já é possivel incluir um depoimento. O site aceita textos, videos, desenhos, fotos, documentos e áudios. Há uma área só para memória oral. Alguns depoimentos são tomados por entrevistadores do Museu, que seguem um roteiro básico de perguntas como idade, formação, onde nasceu, como era a família, profissão, etc. Não são entrevistas, no sentido jomalístico do termo, mas depoimentos de vida. O Museu da Pessoa se articula, portanto, basicamente em cima da memória individual, experienciada. A preservação da memória por meio da museificação parece um movimento que encontra ressonância no que defende Ana Lucia Siaines de Castro, em seu livro Memórias clandestinas e sua museificação. Para a autora, ao abrigar a memória, o museu se revigora, cedendo espaço para inserir-se no debate social, especialmente quando se trata de memórias vinculadas a processos políticos deixados propositamente à margem, como é o caso dos movimentos clandestinos no Brasil durante a ditadura militar.

Aqui se torna importante diferenciar museificação de musealização. A primeira, na proposta de Castro, representa a abertura do espaço institucional do museu para conteúdos que a história oficial não considera. A segunda, seguindo a proposta de Herman Lübbe, descrita por Andreas Huyssen, é uma condição não mais ligada à instituição do museu no sentido estrito, mas uma tendência infiltrada em todas as áreas da vida cotidiana, que inclui a valorização da restauração urbana, o apelo a objetos vintage, até a "autodocumentação na criação das homepages e sites personalizados" (HOLLANDA, 1999). Sua hipótese é que se precisa da memória e da musealização juntas para construir uma proteção contra a obsolescência e o desaparecimento, para combater a nossa profunda ansiedade com a velocidade da mudança e o contínuo encolhimento dos horizontes de tempo e de espaço.

Já Huyssen discorda que a musealização cultural pode proporcionar uma compensação pelas destruições da modernização no mundo social, pois acha que a própria indústria cultural musealizante e a mídia desestabilizam a noção de um passado seguro.

"Quanto mais rápido somos empurrados para o futuro global que não nos inspira confiança, mais forte é o nosso desejo de ir mais devagar e mais nos voltamos para a memória em busca de conforto".(HUYSSEN, 2000: 32) 
Um indício que corroba esta visão de Huyssen pode ser conferido em Os Chegados, quando os depoentes visitam a terra de seus antepassados, e afora a emoção, se sentem como se já conhecessem, como se já tivessem estado lá. Em outras palavras, como se recordassem aquilo que viveram pela memória de outrem. Memórias, portanto, imaginadas.

"Qualquer coisa recordada - pela memória vivida ou imaginada - é virtual por sua própria natureza. A memória é sempre transitória, notoriamente não confiável e passível de esquecimento; em suma, ela é humana e social." (HUYSSEN, 2000: 37) Não é à toa que o personagem de Sebald, Dr. Selwyn, reconhece:

Talvez eu esteja só imaginando isso porque em todos aqueles anos Hedi foi ficando cada vez mais distante de mim, enquanto Naegeli, sempre que surge em meus pensamentos, me parece cada vez mais familiar, ainda que na verdade eu não o tenha visto mais depois daquela despedida. (HUYSSEN, 2000: 20)

A fiç̧ão pode criar vivência e em determinados momentos pode até criar memória. Temos que levar em conta, como pano de fundo, que todas as nossas memórias são midiáticas. O imaginário é um 190 repertório do qual lançamos mão para representar o passado - é dentro desta moldura que experimentamos o evento. $O$ real não pode ser abarcado, ele só é atingido a partir de uma negociação entre o imaginário e a realidade, que produz um relato.

Neste sentido, a memória é um mapa do simbólico que perpassa e organiza tanto o indivíduo quanto o coletivo. Que experiência mais traumática que perder as suas memórias? $\mathrm{O}$ portador de Alzheimer se descobre sem passado - e portanto sem presente, sem identidade. A memória coloniza o passado, ao mesmo tempo em que admite o presente.

\section{Notas}

1 Os três paradoxos são os seguintes: 1 . The objective modernity of nations to the historian's eye vs. their subjective antiquity in the eyes of nationalists. 2 . the formal universality of nationality as a sociocultural concept - in the modern world everyone can, should, will 'have' a nationality, as he or she 'has' a gender vs. the irremediable particularity of its concrete manifestations, such that, by definition, 'Greek' nationality is sui generis. 3. The 'political' power of nationalism vs. their philosophical poverty and even incoherence." (ANDERSON, 1991:14) - Em tradução livre: ".A modernidade objetiva das nações, 
aos olhos do historiador, versus sua antiguidade subjetiva aos olhos dos nacionalistas; 2 . a universalidade formal da nacionalidade como um conceito sócio-cultural - no mundo moderno todo mundo pode, deve, terá uma nacionalidade, da mesma forma como ele ou ela tem um gênero versus a particularidade irremediável de suas manifestações concretas, como por definição, a nacionalidade Grega é única. 3. O poder politico do nacionalismo versus sua pobreza filosófica e mesmo sua incoerência."

2 Em tradução livre: "[A Nação] é imaginada porque os membros da menor nação nunca irão conhecer a maior parte de seus co-membros, encontra-los, ou mesmo ouvir falar deles, ainda que nas mentes de cada um deles viva a imagem da sua comunhão. (...) Todas as comunidades maiores que vilarejos primeiros de contato face a face (e talvez mesmo esses) são imaginadas. (...) A nação é imaginada como limitada porque mesmo a maior delas, englobando talvez um bilhão de seres humanos, tem fronteiras finitas, ainda que elásticas, além das quais existem outras nações. (...) Ela é imaginada como soberana porque o conceito nasceu numa era na qual o lluminismo e a Revolução estava destruindo a legitimidade do reinado de origem divina, dinástico e hierárquico. (...) Finalmente, ela é imaginada como uma comunidade porque, a despeito da desigualdade e da exploração reais que podem prevalecer em cada uma, a nação é sempre concebida como uma confraria profunda e horizontal."

3 Em tradução livre: "Isto é, como um relacionamento com o presente, o qual, de alguma forma, o torna não-familiar e nos permite este distanciamento do imediato qual é caracterizado durante um tempo considerável como una perspectiva hipóstatica."

$4 \mathrm{O}$ canal Futura, mantido pela Fundação Roberto Marinho, foi criado em 1997 e tem uma audiência de 60 milhões de telespectadores, de acordo com dados divulgados pela emissora. A difusão se dá por meio de antenas parabólicas (banda C), TV por assinatura (Net, Sky e DirecTV) e TV aberta.

5Conforme descrito no site do Canal Futura, pitching é uma forma de se apresentar idéias e formatos para um canal de TV com a intenção de co-produção. Trata-se de uma prática comum em feiras de TV internacionais como a International Documentary Film Festival, em Amsterdã (Holanda), ou o Festival de Documentários de Valência (Espanha). No Brasil, este procedimento começa a ser difundido entre 
os canais de televisão, levando as produtoras a investirem no seu capital criativo e estreitando a relação entre produtores e exibidores - uma experiência oportuna para ambos. O canal Futura realizou seu primeiro pitching em 2005, e a segunda edição, em 2006.

\section{Referências Bibliográficas}

ANDERSON, Benedict. Imagined Communities. Londres e Nova Iorque: Verso, 1991

BONNELL, Victoria. Iconography of Power. Londres: University od California Press, 1997.

CASTRO, Ana Lucia Siaines de. Memórias Clandestinas e sua Museificação. Rio de Janeiro: Revan, 2007

COUTO, Renata. Chegados: Como abordar a imigração na TV? In http: www.futura.org.br, acesso em 05/06/2007.

HOBSBAWM, Eric (1983) Introduction: Inventing Tradition. In: Hobsbawm and Ranger, The Invention of Tradition. Cambridge: Cambridge University Press, 1983.pp. 1-14.

HOLLANDA, Heloísa Buarque de. Tantos anos. Caderno Idéias, Jornal do Brasil, 11 de dezembro de 1999.

HUYSSEN, Andreas. Seduzidos pela Memória. Rio de Janeiro: Aeroplano, 2000

Mídia e discursos da memória. Entrevista de Moreira, Sonia Virgínia e Moreno, Carlos A. de Carvalho Moreno. In Revista Brasileira de Ciências da Comunicação. No 1- 2004: Intercom, p-97104.

JAMESON, Fredric. Postmodernism, or, The Cultural Logic of Late Capitalism. Durham : Duke University Press, 1991.

Jornal O Globo. Dois Cafés e a Conta, com Marina Person. Revista O Globo, 29/7/2007, p.6

MUSEU DA PESSOA. Http://www.museudapessoa.com.br . Acesso em 15/06/2007

SARLO, Beatriz. Tempo Passado. São Paulo: Companhia das Letras; Belo Horizonte: UFMG, 2007.

SEBALD, W. G. Os Emigrantes. Rio de Janeiro: Record, 2002. 